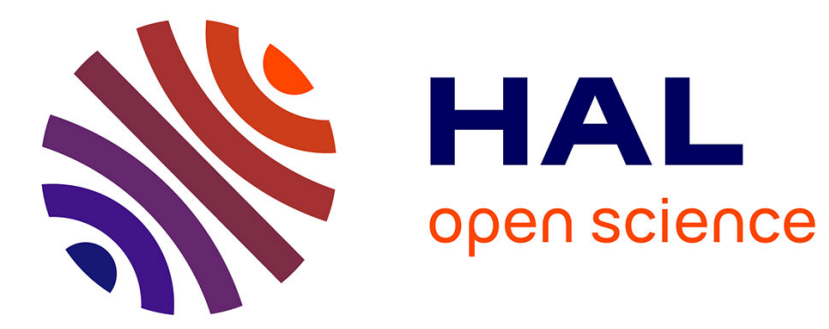

\title{
X-RAY ABSORPTION ON URANIUM SYSTEMS AT VARIOUS THRESHOLDS
}

\author{
G. Kalkowski, G. Kaindl, W. Brewer, W. Krone
}

\section{To cite this version:}

G. Kalkowski, G. Kaindl, W. Brewer, W. Krone. X-RAY ABSORPTION ON URANIUM SYSTEMS AT VARIOUS THRESHOLDS. Journal de Physique Colloques, 1986, 47 (C8), pp.C8-943-C8-948. 10.1051/jphyscol:19868181 . jpa-00226087

\section{HAL Id: jpa-00226087 https://hal.science/jpa-00226087}

Submitted on 1 Jan 1986

HAL is a multi-disciplinary open access archive for the deposit and dissemination of scientific research documents, whether they are published or not. The documents may come from teaching and research institutions in France or abroad, or from public or private research centers.
L'archive ouverte pluridisciplinaire HAL, est destinée au dépôt et à la diffusion de documents scientifiques de niveau recherche, publiés ou non, émanant des établissements d'enseignement et de recherche français ou étrangers, des laboratoires publics ou privés. 


\title{
X-RAY ABSORPTION ON URANIUM SYSTEMS AT VARIOUS THRESHOLDS
}

\author{
G. KALKOWSKI, G. KAINDL, W.D. BREWER and W. KRONE \\ Institut für Atom- und Festkörperphysik, Freie Universität \\ Berlin. Arnimallee 14, D-1000 Berlin 33, F.R.G.
}

\begin{abstract}
We have studied the near edge $\mathrm{X}$-ray absorption fine structure of various metallic and non-metallic $U$ compounds at the $\mathrm{L}_{3}, \mathrm{M}_{3}, \mathrm{M}_{4,5}, \mathrm{~N}_{4,5}$, and $\mathrm{O}_{4,5}$ thresholds using transmission and total-electron-yield techniques. At the $\mathrm{L}_{3}$ thresholds, a chemical shift of $\simeq 4 \mathrm{eV}$ between trivalent and tetravalent $U$ compounds is observed, which drops to $\approx 2 \mathrm{eV}$ between the latter and hexavalent $U$ systems. This indicates extended $5 f$ character and a $5 f$ count close to two in the high oxidation states. The $\mathrm{M}_{4,5}$ thresholds are characterised by intense absorption peaks due to $3 \mathrm{~d}-5 \mathrm{f}$ transitions which show no multiplet structure from $3 \mathrm{~d}-5 \mathrm{f}$ exchange interaction. However, the linewidths of the $M_{4,5}$ peaks decrease by $\approx 20 \%$ with increasing $U-U$ distance in metallic systems, indicating a narrowing of the $5 \mathrm{f}$ band. The soft $\mathrm{X}$-ray absorption spectra at the $\mathrm{N}_{4,5}$ thresholds behave very similarly to the $\mathrm{M}_{4,5}$ edges, except for a vanishing intensity. of transitions into the continuum. Rich structures from 5d-5f exchange interaction are observed at the $\mathrm{O}_{4,5}$ edges of non-metallic $U$ compounds, becoming broadened and partly vanishing in metallic systems, presumably due to the more itinerant nature of the $5 f$ states.
\end{abstract}

\section{INTRODUCTION}

With the increasing availability of synchrotron radiation, $X$-ray absorption (XA) spectroscopy has become a valuable tool for studying the electronic structure of $\mathrm{f}$ and $\mathrm{d}$ electron systems. In particular, from the double-peaked structure of the $\mathrm{L}_{3}$ edges in intermediate valent rare-earth (RE) compounds $/ 1 /$, as well as characteristic multiplet patterns at the $M_{4,5}$ and $N_{4,5}$ edges $/ 2 /$, detailed information on the $4 \mathrm{f}$ configuration has been obtained. For the actinides (An), the amount of available XA data is still limited, although dramatic changes in the $\mathrm{M}_{5}$ edge shape at the $\alpha-$ to- $\delta$ phase transition in $\mathrm{Pu}$ metal have already indicated the sensitivity of XA to changes in the $5 f$ electronic structure $/ 3 /$. Since (in the $\mathrm{keV}$ range) $\mathrm{XA}$ can be performed on encapsulated samples, the method might gain importance under the aspect of providing an experimentally simple access to the electronic structure of the highly radioactive transuranium elements. Very generally, a transition from itinerant to localised character of the $5 f$ states is anticipated at increasing An atomic number $/ 4 /$, the details of which sensitively depend on the specific chemical environment and vary drastically among different compounds of the same An element. Photoemission (PE) and Bremsstrahlung Isochromat Spectroscopy (BIS), showed $\alpha-U$ as well as $\alpha-\mathrm{Pu}$ metal to be itinerant $5 \mathrm{f}$ systems, while $\mathrm{UO}_{2}$ displays localised $5 \mathrm{f}$ character $/ 5 /$. 
To further characterise the method in the An region and provide a basis for future investigations on transuranium systems, we have studied a variety of metallic and non-metallic $U$ compounds by $X A$ at the $L_{3}, M_{3}, M_{4,5}, N_{4,5}$ and $O_{4,5}$ thresholds. A value for the $2 p / 5 f$ coulomb attraction is derived and details of the edge shapes are found to reflect changes in the nature of the $5 \mathrm{f}$ states across the various compounds. We conclude, that considerable information on the electronic structure of An systems may be obtained by XA.

\section{EXPERIMENTAL}

The $\mathrm{L}_{3}$ and $\mathrm{M}_{3}$ measurements were performed in transmission geometry at the ROEMO and EXAFS-2 beamline, respectively, of DESY/Hamburg. By mounting three ionisation chambers in series, the sample and a reference probe could be measured simultaneously for a highly accurate determinition of relative energy shifts. The $\mathrm{M}_{4,5}, \mathrm{~N}_{4,5}$ and $\mathrm{O}_{4,5}$ edges were obtained by recording the total electron yield from the sample and -for normalisation purpose- from a $85 \%$ transmitting $\mathrm{Au}$ or $\mathrm{Ni}$ grid at the monochromator exit. The former measurements were performed at the JUMBO beamline of SSRL/Stanford, while the $\mathrm{N}_{4,5}$ and $\mathrm{O}_{4,5}$ edges were recorded at the SX-700 beamline of BESSY/Berlin. The energy resolution of the various monochromators at the respective thresholds is indicated by $\Delta E$ in Fig. 1 ; more details will be given in a forthcoming publication.

\section{RESULTS AND DISCUSSION}

For $\mathrm{UF}_{4}$ an overview about the various thresholds investigated in this study is given in Fig. 1 on a relative energy scale. According to the dipole selection rules of XA and relative

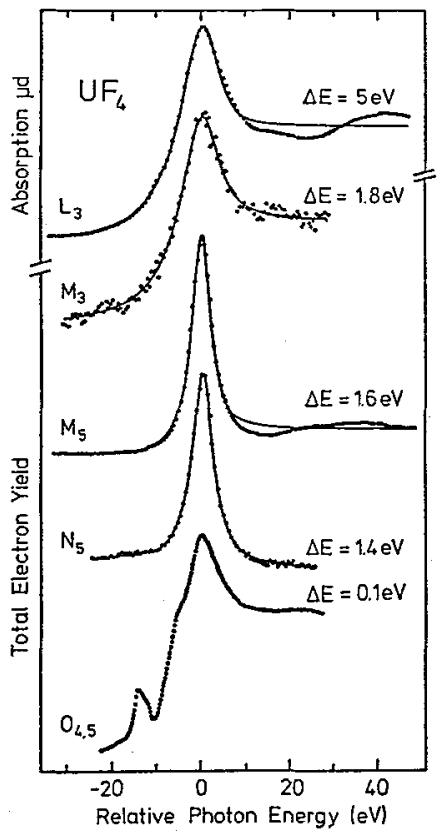

Fig 1: XA spectra of $\mathrm{UF}_{4}$ at various thresholds density of unoccupied states (DOS), the transition at $p$ and $d$ thresholds, respectively, mainly map the $6 \mathrm{~d}$ and $5 \mathrm{f}$ states in the presence of the core-hole. As suggested from this figure and found from comparing the $L_{3}$ and $M_{3}$ edges of various $U$ compounds, both types of thresholds give consistent information on the (final state) $6 \mathrm{~d}$ DOS. This is well expected from the local character of the core hole in both cases and the extended nature of the final states. Also seen in Fig. 1 are the $M_{5}$ and $N_{5}$ thresholds, reflecting the unoccupied $5 f$ states. The great difference in the ratio of the "white line" (WL) to "edge jump" amplitudes between $M_{3}$ and $M_{5}$ demonstrates the much more localised character of the $5 \mathrm{f}$ states relative to $6 \mathrm{~d}$. At the $\mathrm{N}_{5}$ threshold, the intensity of transitions into the continuum is 
vanishingly small, due to the larger wavefunction overlap of $5 f$ states with $4 \mathrm{~d}$ as compared to 3d states. Apparently, no multiplet splitting from core-hole/5f exchange interaction is resolvable at both, the $\mathrm{M}_{5}$ and $\mathrm{N}_{5}$ thresholds, in contrast to the $\mathrm{RE}$ $\mathrm{M}_{4,5}$ edges. At the $0_{4,5}$ thresholds, rich structure from $5 \mathrm{~d} / 5 \mathrm{f}$ interaction similar to the $4 d^{9} 5 f^{n+1}$ excitations in the RE is observed.

A detailed comparison of the $L_{3}$ near edge features in various $U$ compounds is presented in Fig. 2. The WL positions of hexavalent $\mathrm{UO}_{3}$ and trivalent $\mathrm{UCl}_{3}$ are shifted by $\approx 2 \mathrm{eV}$ and $\simeq-4 \mathrm{eV}$, respectively, with respect to tetravalent $\mathrm{UF}_{4}$ or $\mathrm{UO}_{2}$, in qualitative agreement with expectations of more efficient core-hole screening at higher $5 \mathrm{f}$ occupation. Note the shoulder $\simeq 9 \mathrm{eV}$ above the WL maximum in the spectrum of $\mathrm{UO}_{3}$, which reminds of mixed valence features in the RE. A least squares fit analysis by a pair of Lorentzians and arctangent functions similar to that of mixed valent compounds indicates a relative intensity of the satellite feature of $80(20) \%$ and an increase in width by a factor of about three, relative to the WL at lower energy. The shape and relative shifts are reproduced at the $M_{3}$ threshold, where hexavalent uranyl-nitrate shows a single $W L$ and also a shift of $\approx 2 \mathrm{eV}$ relative to $\mathrm{UF}_{4}$. This demonstrates, that the satellite is not generally related to hexavalent $U$ systems, but may indicate multielectron excitations from covalent $\mathrm{U}-\mathrm{O}$ bonding in $\mathrm{UO}_{3}$ or a shape resonance. The small chemical shifts of both hexavalent $U$ compounds relative to $\mathrm{UF}_{4}$ as compared to that of trivalent $\mathrm{UCl}_{3}$ and the satellite feature in $\mathrm{UO}_{3}$ point to an extended $5 \mathrm{f}$ character, in agreement with theoretical estimates of a $5 \mathrm{f}$ count

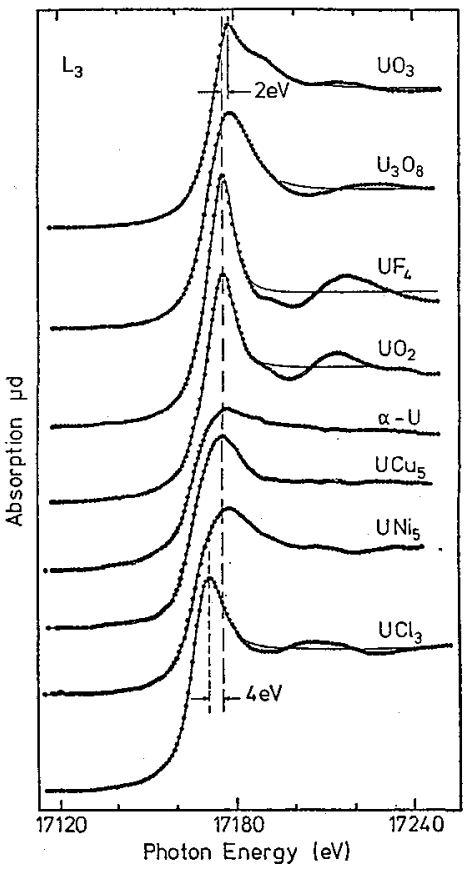

Fig_2: $\mathrm{XA}$ at the $\mathrm{L}_{3}$ thresholds of various metallic and non-metallic $U$ compounds close to two in the even more ionic $\mathrm{UF}_{6} / 6 /$. For $\mathrm{U}_{3} \mathrm{O}_{8}$, where two inequivalent $\mathrm{U}$ sites were formally assigned to penta- and hexavalent $U$ oxidation states, a rather broad and asymmetric WL (shifted by $\approx 3 \mathrm{eV}$ with respect to $\mathrm{UF}_{4}$ ) is observed. This is consistent with the concept of covalent $U-O$ bonds of variable strength. In the metallic systems, the WLs clearly broaden and decrease in amplitude, the effect being most pronounced in $\alpha-U$ metal. In view of the remarkable agreement of one electron band structure based calculations of the $\mathrm{RE}$ metal $\mathrm{L}_{3}$-edges $/ 7 /$, the variations in edge shape among the metals are expected to closely track the inital $6 \mathrm{~d}$ DOS. The unusual chemical shift in $\mathrm{UNi}_{5}$ relative to $\mathrm{UCu}_{5}$ is interesting in view of recent PE/BIS results on the $\mathrm{UNi}_{5-\mathrm{x}} \mathrm{Cu}_{\mathrm{x}}$ series, which point to a more itinerant $5 f$ character in the Ni-rich alloys $/ 8 /$; it may therefore indicate $6 \mathrm{~d} / 5 \mathrm{f}$ hybridisation effects. 
A more direct insight into the 5 f electronic structure is possible from excitations at $d$ thresholds. Fig. 3 presents the $M_{4,5}$ XA spectra of a series of U compounds, together with those of $\mathrm{Th}$ and $\mathrm{ThO}_{2}$ for comparison. Apparently, the shapes are rathersimilar for all the compounds investigated, including "ininerant" $\alpha-U$ as well as "localised" $\mathrm{UO}_{2}$. To determine finer details of the spectra, a least squares fit analysis was performed, using asymmetric Lorentzians for the WLs and arctangent functions for the edge jumps and convoluting with the experimentally determined rocking curves. The results indicate an increase in the $\mathrm{WL}$ widths between $\mathrm{ThO}_{2}(\mathrm{FWHM}=3.5 \mathrm{eV}$ at $\left.\mathrm{M}_{5}\right)$ and $\mathrm{UO}_{2}$ or $\mathrm{UF}_{4}(\mathrm{FWHM}=4.4 \mathrm{eV})$. Among the metallic $\mathrm{U}$ compounds, a decrease in line width by $\approx 1 \mathrm{eV}$ is observed at increasing $U-U$ n.n. distance, approaching the value of $U_{4}$ in case of the $\mathrm{UCu}_{5}$ and $\mathrm{UPt}_{5}$ alloys. Since electrostatic $3 \mathrm{~d} / 5 \mathrm{f}$ interaction is expected to be the larger the more localised the $5 f$ states are, this trend cannot be understood from $3 \mathrm{~d} / 5 \mathrm{f}$ exchange interaction, but rather points to a narrowing of the $5 f$ band from decreasing $f-f$ overlap at larger $U-U$-distances. The relatively small difference in line width between "itinerant" $\alpha-U$ and "localised" $\mathrm{UO}_{2}$ contrasts to the $=50 \%$ decrease in line width and vanishing of the edge jump observed for the $\alpha-$ to- $\delta$ transition in $\mathrm{Pu}$ metal, which was assigned to $5 \mathrm{f}$ localisation $/ 3 /$. This

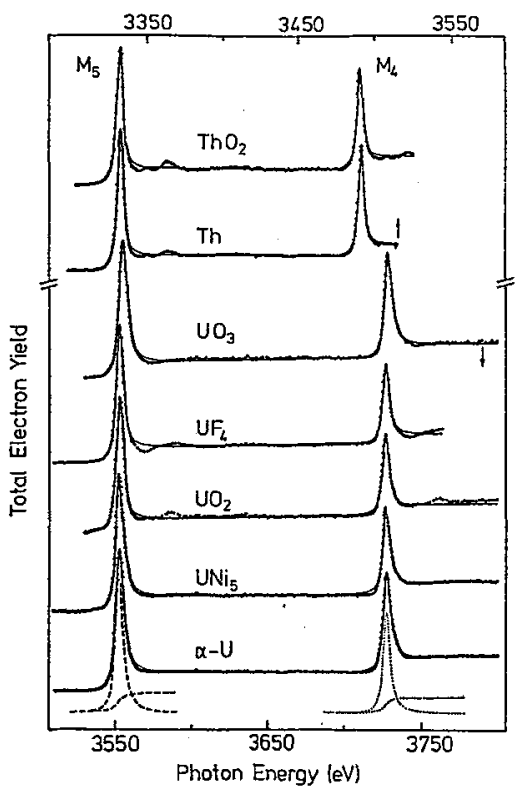

Fig 3: XA spectra of $U$ and $T h$ compounds at the $\mathrm{M}_{4,5}$ thresholds indicates a less dramatic change of the $5 f$ character in the various $U$ compounds as compared in the two $\mathrm{Pu}$ phases and might point to some extended character of the $5 f$ states in $\mathrm{UO}_{2}$ (and $\mathrm{UF}_{4}$ ), in agreement with earlier band structure calculations $/ 9 /$.

The XA spectra of various metallic and non-metallic $U$ compounds and of $\mathrm{ThO}_{2}$ at the $\mathrm{O}_{4,5}$ thresholds are presented in Fig. 4. A close agreement is observed between the the spectral shapes of $\mathrm{ThO}_{2}$ and $\mathrm{LaF}_{3}$ $12 /$, as might be expected from the empty $5 f$ and $4 f$ shell, respectively, in the ground states of the two compounds and large core-hole/5f interaction from intense wavefunction overlap. In particular, the two tetravalent $\mathrm{U}$ compounds $\left(\mathrm{UF}_{4}\right.$ and $\left.\mathrm{UO}_{2}\right)$ show rich structure from $5 \mathrm{~d} / 5 \mathrm{f}$ interaction. The spectrum of $\mathrm{UO}_{3}$ is cleary different from that of $\mathrm{ThO}_{2}$, indicating deviations from a (ionic) $5 \mathrm{f}^{0}$ configuration which would be expected in the limit of completely localised $5 f$ states. In the metallic $U$ systems, the spectral features are less pronounced, presumably due to the more itinerant nature of the $5 f$ states in these compounds. Most striking is the difference in 
spectral shape of the two tetravalent $U$ compounds. There is an additional peak $\simeq 3.5 \mathrm{eV}$ above the giant resonance in $\mathrm{UO}_{2}$, which has no counterpart in $\mathrm{UF}_{4}$, in spite of identical $5 \mathrm{~d}^{9} 5 \mathrm{f}^{3}$ excitations expected for localised $5 f$ levels in the two compounds. In view of its position $\approx 20 \mathrm{eV}$ above the $5 \mathrm{~d}_{5 / 2}$ threshold, this peak might be related to a multiple scattering resonance of the outgoing photoelectron. Comparable features are observed for $\mathrm{UO}_{2}$ at the $3 \mathrm{~d}$ thresholds (see Fig. 3). Alternatively, it may be related to variations in $5 \mathrm{f}$ bonding between the two compounds. One might suspect, that relatively weak differences in crystal field interaction of the $5 \mathrm{f}$ states in $\mathrm{UO}_{2}$ and $\mathrm{UF}_{4}$ can result in pronounced differences for the pattern of dipol allowed transitions probed by XA. Cleary, multiplet calculations of the $5 \mathrm{~d}^{9} 5 \mathrm{f}^{3}$ excited states including crystal field perturbations would be extremely helpful to clearify this point.

\section{CONCLUSIONS}

From the $L_{3}$ XA spectra of tri- and tetravalent non-metallic $U$ compounds a value of $\simeq 4 \mathrm{eV}$ is obtained for the $2 \mathrm{p} / 5 \mathrm{f}$ coulomb interaction and indications are found for extended $5 \mathrm{f}$ states in the formally hexavalent $U$ compounds. At the $M_{4,5}$ thresholds, intense white

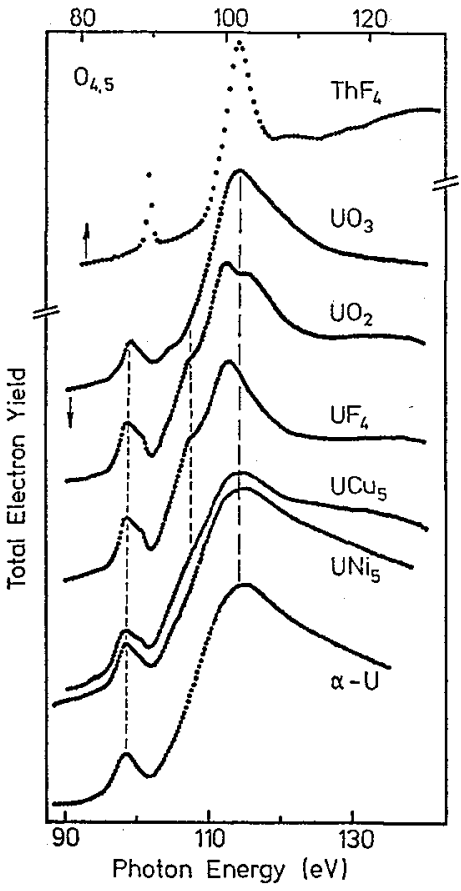

Fig 4: XA spectra at the $\mathrm{O}_{4,5}$ thesholds lines demonstrate the more localised (narrow band) character of the $5 \mathrm{f}$ states relative to $6 \mathrm{~d}$. Variations in line width of $\approx 20 \%$ among the metallic systems are consistent with expectations of a narrowing of the $5 \mathrm{f}$ band at increasing $\mathrm{U}-\mathrm{U}$ distance. No multiplet splitting from core-hole/5f exchange interaction is observed. at both, the $\mathrm{M}_{4,5}$ and $\mathrm{N}_{4,5}$ thresholds. This interaction, however, leads to rich structure at the $\mathrm{O}_{4,5}$. thresholds, particularly in the non-metallic $U$ compounds investigated. Differences in the $\mathrm{O}_{4,5}$ edge shapes of the two tetravalent $U$ compounds $U_{4}$ and $\mathrm{UO}_{2}$ may reflect extended contributions in the $5 f$ character of these compounds or be due to multiple scattering effects similar to those at the $M_{4,5}$ thresholds.

\section{ACKNOWLEDGEMENT}

We gratefully acknowledge Prof. B. Kanellakopulos for providing the $\mathrm{UCl}_{3}$ sample und Dr. C. Laubschat, Dr. M. Domke, G. Schmiester, Dr. E. Paparazzo, and A. Schach v. Wittenau for valuable assistance. 


\section{REFERENCES}

1/ see: Proc. of the $4^{\text {th }}$ Internat. Conf. on Valence Fluctuations, edited by E. Muller-Hartmann, B. Roden, and D. Wohlleben, North Holland (1985)

/2/ G. Kaindl et al,, J. Magn. Magn. Mater. 41\&42, 181 (1985); W.D. Brewer et al., Phys. Rev. B32, 3676 (1985); G. Kalkowski et al., Phys. Rev. B32, 2717 (1985)

/3/ C. Bonnelle et al., in: Plutonium and other Actinides, edited by H. Blank and E. Lindner, North Holland (1976), 343

14/ M.S.S. Brooks et al., In: Handbook on the Physics and Chemistry of the Actinides, edited by A.J. Freeman and G.H. Lander, North Holland (1984), p. 153

/5/ Y. Baer, p. 271 in ref. /4/

16/ D.D. Koelling et al., J. Chem. Phys. 65, 3331 (1976)

/7/ G. Materlik et al., Phys. Rev. Lett. 50, 267 (1983)

/8/ F.U. Hillebrecht et al., Phys. Rev. B33, 4376 (1986)

/9/ M.S.S. Brooks et al., Solid St. Comm. 45, 689 (1980) 